\title{
MANUAL DEL VIAJERO EN MÉXICO (1858), DE MARCOS ARRÓNIZ. APUNTES EN TORNO A UN NARRADOR COSTUMBRISTA
}

\section{Manual del viajero en México (1858), by Marcos Arróniz. Notes about a costumbrista narrator}

Gerardo Francisco Bobadilla Encinas

Fecha de recepción: 29 de agosto del 2018

Fecha de aceptación: 13 de marzo del 2019

1- Nacionalidad: Mexicana. Grado: Doctorado. Especialización: Literatura. Adscripción: Universidad de Sonora. Correo electrónico: gerardofranciscobobadilla@gmail.com. ORCID: http://orcid.org/0000-0001-9434-6528 


\section{Resumen}

Una de las grandes lagunas de la literatura mexicana del siglo XIX está referida al estudio y conocimiento de la segunda generación romántica y de las características de la literatura costumbrista escrita entre 1836 y 1855. Con la intención de subsanar esas omisiones, el presente ensayo busca estudiar una de las figuras más representativas de esa generación, Marcos Arróniz, quien aparte de ser un adelantado a su época en el ámbito de la lírica, fue una figura que pudo revolucionar la práctica costumbrista en la tradición narrativa nacional.

Palabras clave: Historia literaria mexicana; Costumbrismo mexicano; Relaciones pintura/literatura; Marcos Arróniz.

\section{Abstract}

One of the great omissions in Mexican literature of the nineteenth century is referred to the study and knowledge of the second romantic generation and the characteristics of the literature of manners written between 1836 and 1855. With the intention of correcting these omissions, the present essay seeks to study one of the most representative figures of that generation, Marcos Arróniz, who apart from being ahead of his time in the field of lyric, was a figure who could revolutionize the practice manners in the national narrative tradition.

Keywords: Mexican literary history; Mexican costumbrismo; Lithography / Literature relations; Marcos Arróniz. 
a imagen de Marcos Arróniz como el arquetipo del poeta romántico mexicano, ensimismado y atribulado, que literaturiza su vida y enloquece y muere de febricitante consunción amorosa, fue configurada, sobre todo, por las semblanzas necrológicas y memoriosas que sus coetáneos Juan Díaz Covarrubias (1837-1859) y José Zorrilla (1817-1893), dolidos, escribieron tras su muerte ocurrida en diciembre de 1858. Dichos panegíricos le crearon un perfil trágico que, dentro del parnaso mexicano decimonono, sólo comparte con Ignacio Rodríguez Galván (18161842) y Manuel Acuña (1849-1873).

Esta aura romántica existencial se ha impuesto a tal grado dentro del horizonte literario e historiográfico de México que ha impedido conocer realmente tanto su biografía como, más importante, su obra concreta. En el siglo XIX intelectuales de la talla de Ignacio Manuel Altamirano en el prólogo a Pasionarias (1882), de Manuel Acuña, y Francisco Pimentel en su Historia crítica de la poesía en México (1893), en nuestro siglo estudiosos como Marco Antonio Campos en "Vida y obra de Marcos Arróniz" (2005) o Ángel José Fernández en "Marcos Arróniz y sus amigos del Liceo Hidalgo" (2005), han escrito sendos trabajos en donde buscan eludir esa mitología, reconstruyendo la vida y la evolución artística del poeta mediante sesudas investigaciones, cotejos documentales y recuperación de su obra: sin embargo, el peso de la leyenda del vate sigue imponiéndose a los resultados autorizados e ilustrativos de sus averiguaciones y no han podido borrar en los todavía pocos lectores que se acercan a sus textos la comprensión de la existencia y obra de Marcos Arróniz con base en la leyenda del héroe romántico trágico.

En este contexto, se asume que Marcos Arróniz perteneció a la generación literaria de los escritores mexicanos nacidos entre 1825-1835 aproximadamente, pues Luis Gonzaga Ortiz (1832-1894) lo considera de su misma camada y camarilla junto con Francisco González Bocanegra (1824- 1861), Florencio María del Castillo (1828-1863) y Francisco Zarco (1829-1869), todos ellos, pese a sus diferencias de carácter e ideológicas, entrañables y dilectos amigos, por lo que podría decirse que el poeta fue uno de los mosqueteros de la literatura romántica mexicana durante la década comprendida entre 1850-1860. Y como una especie de D’Artagnan del grupo, a contracorriente de la vertiente mexicanista imperante entonces y que cultivaban sus compinches, Arróniz desarrolló en lo individual algunos de los tópicos, más importante, algunas de las perspectivas que posteriormente caracterizaron al segundo romanticismo mexicano que tuvo su auge en México después, entre 1867 y 1890 aproximadamente.

Mitificaciones aparte, en este contexto debe reconocerse que Marcos Arróniz fue un anticipado a su época. Y es que el vate escribió una obra poética que aborda los temas y perspectivas del amor frustrado, la identificación anímica del hombre con la naturaleza, la incomprensión, la soledad, el hastío, la muerte, todos tópicos románticos que, aunque conocidos y cultivados en su época, como decía antes sólo hasta la consumación definitiva de la segunda independencia de México en 1867, luego de la caída del frustrado imperio de Maximiliano de Habsburgo y la instauración de la república restaurada, se establecerían como las directrices temáticas y perceptuales que condujeron el desarrollo del segundo romanticismo como antesala a la poesía modernista. Habría que puntualizar que la originalidad de su propuesta artística se destaca en un contexto histórico, cultural y literario vertebrado por la dominante mexicanista de la Academia de Letrán, en el marco de la cual escribe un conjunto de obras de diversos géneros que publicó entre 1851 y 1856, dotado de unas poderosas pluma y sensibilidad con las que visualizó y expresó no sólo temáticas nacionalistas sino también el intimismo, la melancolía, y la dinámica contradictoria de la 
lucha de los opuestos a través de unos versos rítmicos y sonoros ${ }^{2}$. A esto añade Esther Martínez Luna que su producción también plantea "rasgos particulares y diferentes que Arróniz hizo salir de su pluma [... entre los que considera] es digno de destacar que su obra poética tiene matices pronunciados de la poesía pastoril y arcádica" (2008: 135), lo que por su parte Marco Antonio Campos interpreta sugerentemente como la influencia de Garcilaso de la Vega (2007: 36).

Pese a que se manejan diversas explicaciones referidas a su lugar de nacimiento (referencias temáticas en algunos poemas; asociación del apellido con específicas regiones de la geografía del país), Francisco Pimentel, su amigo y confidente, zanja la cuestión al afirmar categórico que "Arróniz nació en Orizaba[, Veracruz,] de padres pertenecientes a una buena familia" (1892: 840). Asimismo debe señalarse que murió a mediados de diciembre de 1858, a manos de alguna de las gavillas de forajidos que merodeaban entre la Ciudad de México y Puebla, cuando deambulaba mentalmente alienado llorando sus penas de amor por esos caminos de Dios.

De manera paradójica, incierta, se reconoce su filiación política e ideológica santanista, la que él explicaba, unas veces, como resultado de la convicción y, otras, como fruto del "desengaño cruel y la traición amorosa de la que había sido objeto" (Fernández, 2005: 133), de lo que resultaban su filiación y participación públicas meros escapes a los problemas y frustraciones de su existencia: como capitán de lanceros de Antonio López de Santa Ana tenía una existencia activa, móvil, que, supuestamente, le permitía tomar distancia (al menos física) del sin vivir de su existencia, una desdeñosa (e incógnita) mujer amada que lo rechazaba. Esta misma ambigüedad ideológica quizás ayude a entender el hecho de que su adscripción a la dictadura santanista no le impidió, sin embargo, hacer amistad e integrarse a las actividades culturales y literarias que realizaban personajes emblemáticos del México de la época con credos distintos al suyo, como Francisco González Bocanegra --el autor del "Himno nacional"--, Francisco Zarco --el iniciador de esa crónica satírica tan mordaz e incisiva-- y el imprescindible y nacionalista aunque todavía muy joven Ignacio Manuel Altamirano.

Como decía antes, sus primeras participaciones en la vida cultural y literaria mexicana están fechadas en 1849, pues se tiene constancia que fue vocal del Liceo Hidalgo en ese entonces, aunque, como señala Marco Antonio Campos (2005: 119), realmente su obra artística comenzó a aparecer publicada en los periódicos y revistas literarias entre los años de 1851 y 1856. Según está documentado, "sus poemas, prosas poéticas y artículos aparecieron [...] en [...] La Ilustración Mexicana, El Presente Amistoso y Álbum de las señoritas mexicanas, y [en] los diarios El Siglo Diez y Nueve [...] y El Monitor Republicano" (Campos, 2005: 118).

Por todo lo anterior, lo único claro y definitivo en torno a Marcos Arróniz es su filiación romántica, así como su admiración y seguimiento a la poética de Lord Byron y José de Espronceda, lo que en mucho condiciona la construcción y manejo del verso, la esencia dinámica y tensa, contradictoria y apasionada, de la imagen poética. En este contexto es pertinente señalar que sus poemas y traducciones de bardos ingleses y franceses --la mayoría de los cuales compiló y prologó Marco Antonio Campos bajo el título de La lira rota (2007)-- son "punto de partida para [iniciar o] continuar con el estudio de la segunda generación de escritores del romanticismo mexicano, pues esta generación fue determinante en la construcción de nuestra república literaria" (Martínez, 2008: 135), y la cual ha sido tan injustamente soslayada por la Historia de la literatura, quizás por lo propositivo de la anterior, la de los miembros de la Academia

2- Influencia, sin duda, de sus reconocidísimos Byron, Zorrilla y Espronceda. 
de Letrán, o por la influencia y trascendencia de la posterior, la de los poetas de la Reforma. El caso es, pues, que el conocimiento y estudio de la obra de Marcos Arróniz y la del grupo de que formó parte constituyen una de las lagunas más sensibles en el conocimiento de la literatura mexicana del siglo XIX, más todavía cuando se advierte que fue, que fueron, no sólo sensibles poetas, sino, también, excelentes articulistas de costumbres.

En 1855, Joseph Decaen, el impresor francés mexicanizado, dirigió y publicó la que, a mi parecer, es, junto con Los mexicanos pintados por si mismos (editado en libro ese mismo año), una de las cimas del primer costumbrismo mexicano ${ }^{3}$. Me refiero a México y sus alrededores. Colección de vistas monumentales, paisajes y trajes del país, atlas que reúne una colección de cuarenta y ocho retratos plásticos y literarios, clasificados en treinta y siete vistas, siete representaciones de trajes y tipos, dos de escenas costumbristas y una museográfica, además de un plano general de la Ciudad de México. Como había sido establecido y practicado con asiduidad desde principios de la década de 1840 en diversos artículos costumbristas publicados en los principales periódicos y revistas culturales y literarios de la época, este tipo de textos habían ya definido una resolución artística basada en la composición integrada de dos discursos, el literario y el visual, conformando sendos binomios en los que la litografía y la literatura como parte de las Bellas letras, participaron junto con otras manifestaciones en la mexicanización discursiva, icónica y valorativa del México independizado en 1821 y del cual apenas se estaba apropiando la colectividad.

México y sus alrededores. Colección de vistas monumentales, paisajes y trajes del país estuvo a cargo, plásticamente, de los excelentes e imprescindibles litógrafos Casimiro Castro, José Campillo y Guadalupe Rodríguez, quienes testimonian con sus trabajos de las décadas de 1840 y 1850 sobre todo, la madurez y el dominio adquirido sobre la técnica que hacía apenas veintiséis años habían introducido en México Claudio Linatti y Florencio Galli y que, balbuceante, pervivió hasta que en 1843 comenzó a adquirir carta de naturalización en la cultura mexicana. La composición de los artículos literarios de México y sus alrededores, por su parte, fue obra de José María Roa Bárcena, José Tomás de Cuéllar, José María González, Hilarión Frías y Soto, Manuel Payno, Anselmo de la Portilla, Vicente Segura Argüelles, Francisco Zarco, Niceto de Zamacois... y, cómo no, de los mosqueteros del romanticismo mexicano, esto es, de Florencio María del Castillo, Francisco González Bocanegra, Luis G. Ortiz y, por supuesto, Marcos Arróniz.

La colección de vistas publicada en 1855 obedecía a un claro y asumido objetivo, que, cabalmente, expresaba Francisco Zarco en el cuadro literario/plástico con el que comienza la obra, el titulado "La fuente del Salto del agua”.

3- La historia de la literatura mexicana realmente ha estudiado poco las manifestaciones del costumbrismo decimonono, reduciendo sus señalamientos a generalidades que repiten acríticamente lo dicho para el caso español.

Por ello, como se ha dicho con mayor detenimiento en algún otro espacio (Bobadilla, 2013), el Costumbrismo en México fue un movimiento narrativo que recorrió transversalmente la literatura decimonona, determinado por la imperante nacionalista posindependentista (1821-1867) primero, por el espíritu positivista de la república restaurada después (1867-1890). Esto configuró dos grandes momentos en el desarrollo del movimiento en México: el que puede llamarse como el primer costumbrismo (1843-1867), caracterizado por el cultivo y desarrollo que tuvieron los artículos de tipos, escenas y paisajes naturales y urbanos sobre todo a partir de la década de 1840, como resoluciones éticas y estéticas concretas que buscaban reconocer y retratar física y moralmente a México y el mexicano para articular una palabra y un código identitario propio, el cual estuvo representado por escritores como Guillermo Prieto, Manuel Payno, Hilarión Frías y Soto, entre otros, y que estuvo grandemente influenciado por la perspectiva paternal y empática del costumbrismo español representado por Ramón de Mesonero Romanos y Serafín Estébanez Calderón; por otro lado se encuentra lo que se reconoce como el segundo costumbrismo, que encontró en la novela la resolución artística mediante la que se ejerció, sobre todo, una crítica moral a la clase media, como posibilidad de trascendencia y regeneración social, etapa deudora del punto de vista ácidamente satírico de Mariano José de Larra, el cual asumen y desarrollan, sobre todo, narradores como José Tomás de Cuéllar y Ángel de Campo. 


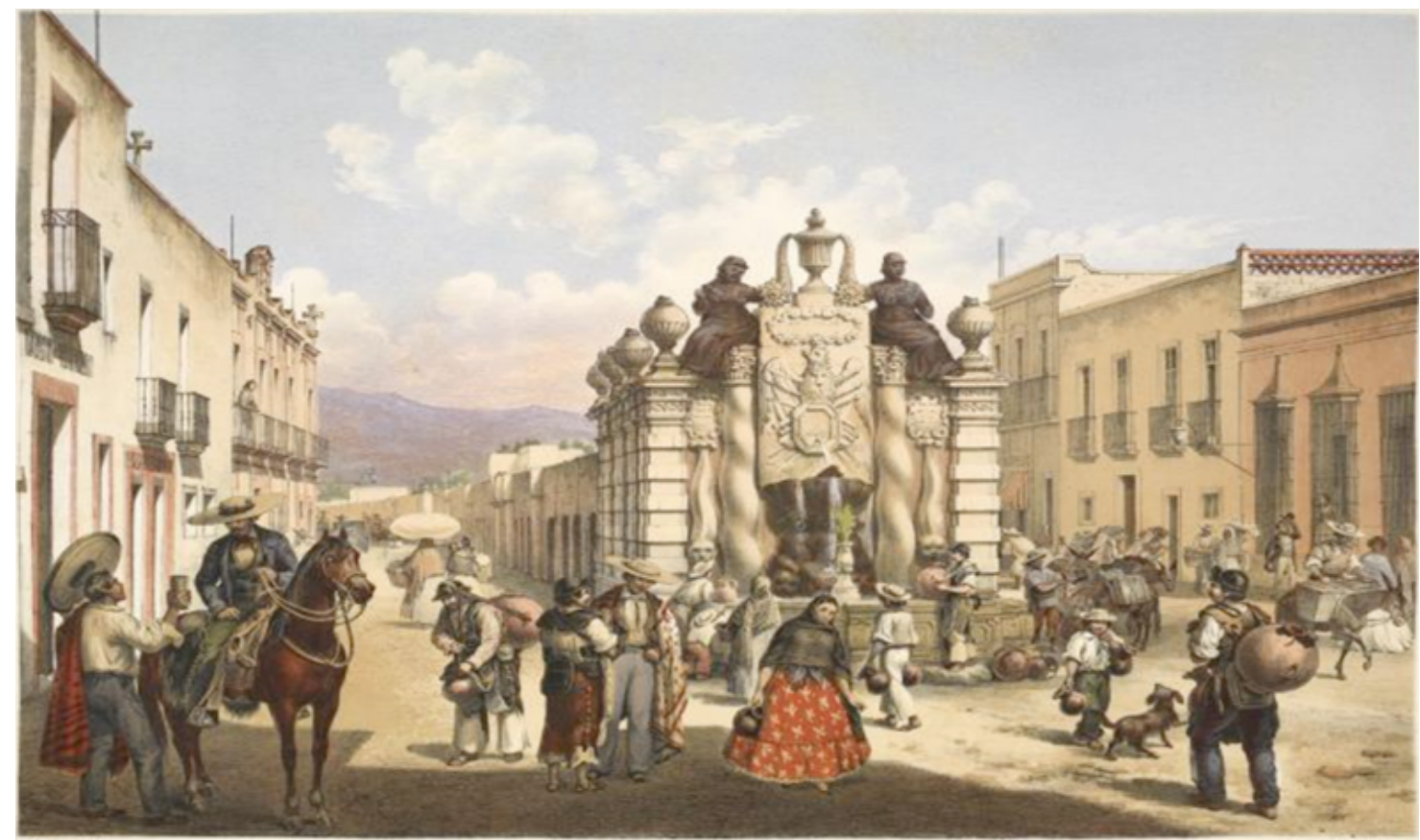

"La fuente del Salto del agua" en México y sus alrededores (1855)

En dicho texto, más que describir al surtidor, el texto literario reflexiona acerca de la identidad de México y el mexicano en los siguientes términos:

No somos aztecas, no somos españoles; raza bastarda de las dos, tenemos la indolencia de la una, la arrogancia de la otra; pero aun no constituimos una raza propia, distinta de las demás con cualidades, buenas o malas. Pueblo de ayer, sin tradiciones, sin grandes recuerdos, nuestra historia de pocos años es la crónica de la inexperiencia, de la locura y de la discordia y falta a nuestros acontecimientos más notables ese prestigio fascinador de la distancia que dan a los hombres y a las cosas los montones de siglos que se interponen entre las generaciones (1855: 4; el subrayado es mío).

...Una identidad y una historia amorfas y sin tradición son los factores que se asumen como caracterizadores de la cultura mexicana para el momento de la enunciación, 1855: la lógica expositiva asocia identidad e historia con la existencia de testimonios artísticos, arquitectónicos, que den cuenta del desarrollo y complejidad de una cultura. Aunque el texto de Zarco plantea que en México no hay monumentos con significado pues no hay historia --soslayando muy convenientemente lo dicho por el barón de Humboldt, en el que, por otro lado, se apoya--, el sentido y la función que a partir de esta afirmación se otorga y cumplen las vistas y retratos plásticos y literarios de México y sus alrededores es el de crear, de inventar precisamente esa historia: la estructura básica de significación de la unidad retrato plástico/retrato literario está enfocada sobre todo a otorgar representatividad y trascendencia histórica a la cultura nacional, a partir de la contextualización de los edificios y espacios descritos tanto plástica como literariamente; en este sentido, pues, a partir de la descripción literaria de las vistas, los narradores articulan un entramado histórico que les permite rastrear el surgimiento de un sentimiento patriótico y de un orgullo nacional mexicano desde la época de la colonia. 
Creo necesario problematizar en este contexto el reconocimiento que hacía Zarco referido al hecho de que la existencia de monumentos es vestigio de la madurez de una cultura. Y es que el escritor, al plantear la carencia de dichos vestigios y, según la lógica imperante, la carencia de una historia nacional propia, señala como al paso y humildemente que lo único que México tiene y de lo que puede vanagloriase, es su naturaleza diversa, fértil y fructífera:

Durante ese periodo de tres centurias [que fue la Colonia...] escasean los acontecimientos notables y dramáticos [en México] que dan lugar a pintorescas y vivas tradiciones, y que se graban en la memoria de los pueblos sin borrarse jamás. Pueblos que no tienen vida propia no tienen historia [ni cultura]; sus acontecimientos son figuras secundarias destinadas a aparecer en último término en otro cuadro [, el cuadro ajeno de la historia del país dominador].

[... Por eso, México es] ¡Un pueblo sin monumentos!

[... Sin embargo,] lo que hay aquí que describir vale más que las masas de piedra. Ahí está el Popocatépetl coronado de nieve; allí las serranías erizadas y salvajes; allí los jardines que halagan a un tiempo la primavera y el otoño en la Tierra-caliente; en otra región llanuras inmensas, costas fértiles bañadas por el mar que apenas las acaricia con amor; bosques vírgenes, sabinos y ahuehuetes que nacieron el día de la creación... Aquí se estudia la obra de Dios, que es más grande que la de los hombres (Zarco, 1855: 4-5; el subrayado es mío).

Descrita la naturaleza mexicana al mejor estilo romántico, esto es como proyecto que debe su riqueza y armonía gracias a la benignidad y generosidad del Todopoderoso, la obra México y sus alrededores se da a la tarea de describir las "sublimes catedrales y magníficos palacios; [los] galanos acueductos y hospitales; [los] colegios y prisiones; [las] plazas y fuentes" (Zarco, 1855: 5) que pueblan y enriquecen a la Ciudad de México. Y aquí está lo importante, el artificio ético y estético que sólo la hermandad de la literatura y la pintura, la litografía, pudieron resolver: se realizan una serie de descripciones que representan y explican la calidad artística y la grandiosidad y magnificencia de las edificaciones, fuentes y plazas, sólo que, lo más importante, esas obras monumentales que son la catedral metropolitana, la plaza de la constitución, el Palacio de Minería o las casonas de Tacubaya, se visualizan siempre en medio del exuberante y pródigo marco que supone el entorno americano, integradas franca y espontáneamente a la naturaleza mexicana, gracias a la perspectiva aérea, elevada del pintor --entonces se pusieron de moda en México los paseos en globos aerostáticos que permitieron esa nueva percepción--. En este sentido, la colección contribuye a la conformación de un espacio-tiempo cultural e histórico mexicano a partir de establecer una contigüidad fundacional entre el proyecto divino que es la naturaleza mexicana y los monumentos y edificaciones que lo pueblan.

Me he detenido en describir y explicar los pormenores de la intencionalidad ética y estética que Francisco Zarco define y otorga a México y sus alrededores a partir del cuadro "La fuente del Salto del agua", por un lado, porque, como lo han reconocido algunos de los pocos estudiosos de la obra, de esta manera el compendio puntualiza y justifica desde el principio la finalidad del enunciado plástico/literario que es el atlas, marcando al mismo tiempo los parámetros a partir de los cuales se busca dotar de significado 
- Revista de Ciencias Sociales y Humanidades. ISSN-P: 0188-9834 ISSN-E:2395-8669.

y sentido histórico al espacio-tiempo natural y cultural mexicano que se descubría y reconfiguraba discursiva e iconográficamente. Pero también y sobre todo, me he detenido en exponer la función artística del texto que enuncia Zarco, porque, considero, el cuadro litográfico/literario titulado "La fuente de la Tlaxpana”, escrito por Marco Arróniz, es, de todos los cuadros incluidos en la conformación artística del atlas, el que mejor sintetiza y resuelve ética y estéticamente el propósito del compendio ${ }^{4}$, incluso con una calidad literaria superior al texto de Fortún (pseudónimo de Zarco) comentado antes.

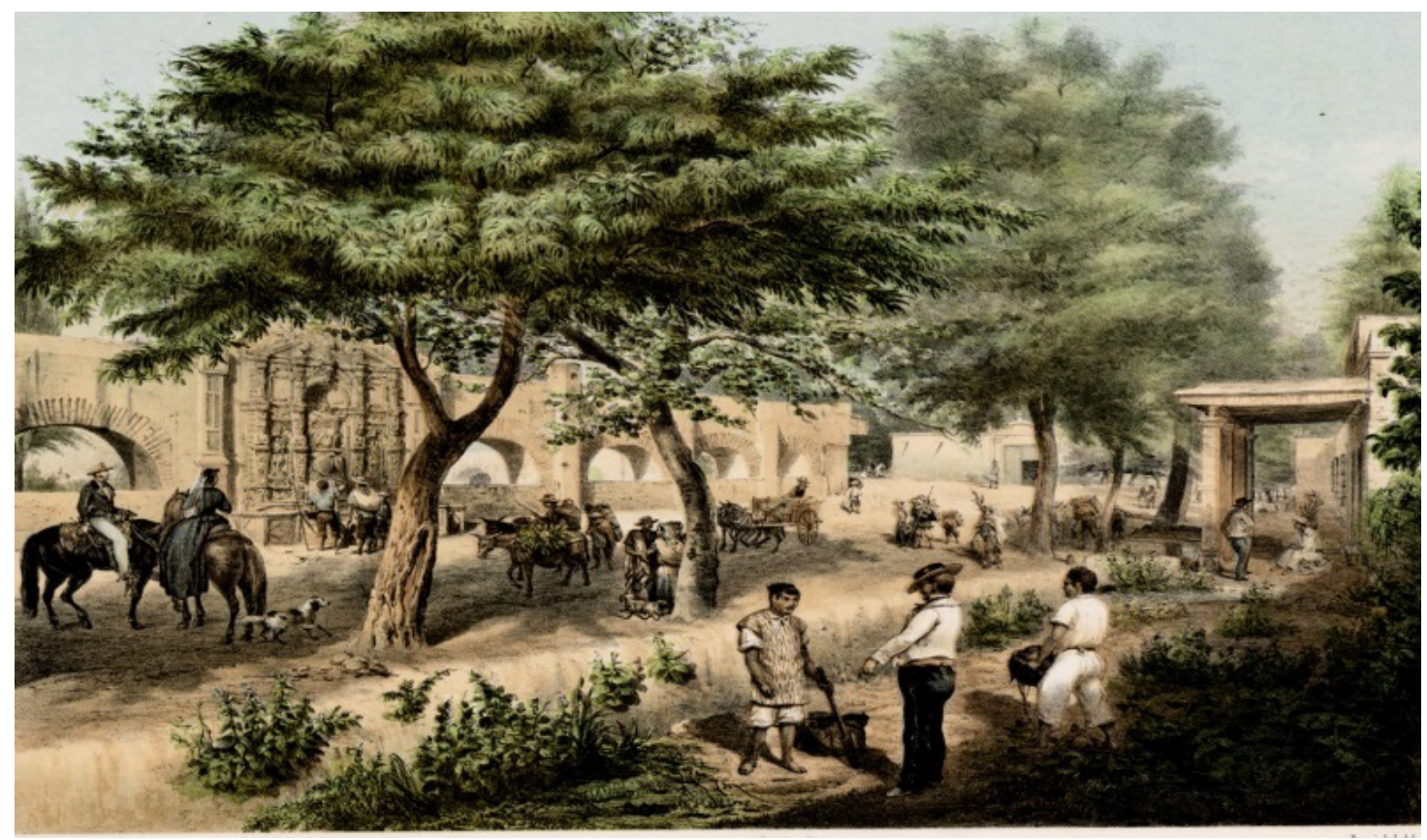

"La fuente de la Tlaxpana" en México y sus alrededores (1855)

Atendiendo las particularidades del género, "La fuente de la Tlaxpana" realiza la descripción y ubicación física e histórica del monumento en los siguientes términos:

A la salida de la capital, por el noroeste, en la calzada de San Cosme, se encuentra la fuente llamada de la Tlaxpana, incrustada en los arcos que conducen el agua delgada desde Santa Fé. Nada tiene de monumental, y parece a primera vista más bien recuerdo de alguna antigüedad mexicana que una obra construida por los españoles; se ven algunos adornos del gusto de la época; figuras con instrumentos de cuerda, bajos y violines, y las armas de la casa de Austria: dos inscripciones nos dicen que fue construida en 1737, siendo arzobispo y virrey de la Nueva España D. Juan Antonio Bizarrón y

4- En el proyecto inicial, el texto plástico-literario "La fuente de la Tlaxpana", de Marcos Arróniz, abriría el compendio. Sin embargo, de último momento, Joseph Decaén, el impresor y director de la obra, consideró que la reflexión y contextualización histórica de Zarco, si bien más histórica y filosófica, explicaba con mayor concisión la intencionalidad ética de la obra, motivo por el cual decidió que abriera la compilación. 
Eguiarreta. Dicha obra pertenece al género a que ha dado su nombre por lo extravagante y atrevido el conocido Churriguera, que viene a ser el Góngora de la arquitectura. $\mathrm{Y}$ advertiremos de paso, que en México, construidos los edificios principales, poco más o menos en una misma época, adolecen de unos mismos defectos en su gusto arquitectónico (Arróniz, 1855: 6).

Como puede advertirse, el narrador del cuadro costumbrista ubica puntualmente la situación del monumento, hecho que otros autores de algunas de las descripciones de la colección llegan al puntillismo de señalar grados y latitudes, cantidades de los materiales empleados en la construcción. Revelando los parámetros valorativos de la ideología dominante entonces, el antiespañolismo particularmente ${ }^{5}$, puede advertirse que el narrador incurre, incluso, en ciertos comentarios o interpretaciones que intentan neutralizar las características y el valor arquitectónico y cultural del surtidor al asociarlo a una ideología y una época, la colonial --dejando de lado que era una verdadera joya del más genuino barroco americano, considera Manuel Toussaint (1934)--, como cuando señala que la Fuente de la Tlaxpana "nada tiene de monumental [...pues está constituida por] algunos adornos del gusto de la época [...perteneciendo la obra] al género a que ha dado su nombre por lo extravagante el conocido Churriguera, que viene a ser el Góngora de la arquitectura" (Arróniz 1855: 6). Reconociendo y explicando desde el horizonte de expectativas de su contexto las interpretaciones anteriores, en lo personal, me parece que la trascendencia ética y estética del texto costumbrista de Arróniz se encuentra en la capacidad y sensibilidad del narrador para retratar dinámica y dialécticamente no sólo el sentido o dimensión histórica del venero, sino, sobre todo, por captar las particularidades del conjunto humano y cultural que confluye en torno a la Fuente de la Tlaxpana. Y es que pese a considerar a partir de los parámetros antihispanistas

que esta construcción no se distingue por su belleza arquitectónica, sirve para animar la escena; por un lado el sólido acueducto, cuyos arcos a manera de grandes lentes dejan ver a lo lejos paisajes tranquilos y risueños; la fuente con sus adornos grotescos donde se acercan algunos indígenas a apagar la sed, vestidos con sus curiosos trajes; el indio que pasa lentamente con su hijo a cuestas y arreando sus jumentos cargados de verduras; ora se detiene gallarda joven en su brioso corcel con el caballero que la acompaña, a contemplar los indios carboneros que vienen; el ruidoso carro de harina que cruzó, dejando una nube de polvo; todo, todo presenta vida, movimiento y alegría. Allá en el fondo se contempla el Panteón de los ingleses, contrastando su fría calma con la animación exterior; unos frondosos árboles y algunas casas sencillas vienen a completar el cuadro (Arróniz, 1855: 6).

Resulta particularmente interesante señalar que lo que importa al narrador del cuadro no es la monumentalidad churrigueresca de la fuente (que, por lo demás, en su época fue considerada la Fuente de Trevi mexicana, pese a la descripción y valoración neutral del narrador), sino el fluir dinámico y vital del

5- Vid. Ignacio Ramírez, “La desespañolización” (1865); José Luis Martínez, La emancipación literaria de México (1855); Luis Mario Schneider, Ruptura y continuidad. La literatura mexicana en polémica (1975); David Brading, Los orígenes del nacionalismo mexicano (1997). 
pueblo mexicano, con todo y sus contrastes sociales y existenciales, los de la vida y la muerte incluso con la referencia al Panteón de los ingleses que es el punto de fuga del cuadro plástico-literario, en un guiño o indicio al lector mediante el que se busca expresar la cotidianidad dialéctica de la vida y la muerte. En este sentido y a diferencia de los otros que conforman a México y sus alrededores, el cuadro plástico/literario "La fuente de la Tlaxpana" es indicador de las posibilidades renovadoras que, como narrador, Marco Arróniz ofrecía a la práctica costumbrista mexicana, hecho que refrenda pocos años después, en 1858 , cuando escribe y publica Manual del viajero en México o compendio de la historia de la ciudad de México.

Manual del viajero en México o compendio de la historia de la ciudad de México, de Marcos Arróniz, es una obra editada en 1858, en París, por la mexicana Librería de Rosa y Bouret. El texto se inserta dentro de la tradición de los manuales o guías de viaje que, luego de su auge a partir de 1828, se establecieron como un género discursivo específico y propio del siglo XIX que expresaba la modernidad del nuevo entorno capitalista-burgués, misma que se entendía como acceso, como libertad de movimiento del individuo por el mundo. Debe recordarse que desde que el alemán Karl Baedeker inventó el género dicen unos, lo reinsertó dentro del horizonte cultural y literario romántico burgués moderno dicen otros, los viajantes modernos tuvieron la oportunidad de acceder a diversos datos geográficos, topográficos, culturales, mediante los que podían desenvolverse de manera independiente ante nuevos espacios y realidades culturales al incluir la más diversa información --desde la descripción de monumentos, usos y costumbres locales y rutas por las ciudades, hasta horarios de transportes, precios de hoteles y entradas a monumentos-- ${ }^{6}$.

Así pues, y como sucedía en y con otras grandes ciudades de Occidente --París, Londres, Roma, Nueva York--, la Librería de Rosa y Bouret encargó a Marcos Arróniz la elaboración de Manual del viajero en México o compendio de la historia de la ciudad de México ${ }^{7}$, el cual ha trascendido como la que

parece ser la primera guía de viajeros en México, en la que [se] proyecta una imagen de lo que somos o de cómo este joven escritor ve a su país y a sus habitantes para contraponerla a la forma en que nos veían los extranjeros, llena de estereotipos muy deformados y deformantes [... Y es que] visionariamente a Arróniz se le ocurre que a una imagen se le pueden acercar otras para formar un cuadro o visión más compleja, plural y articulada que muestre no sólo a la comunidad que él está observando, sino la manera en que una comunidad observa a otra y/o se observa a sí misma (Martínez Andrade, 2008: 94).

Así surge el Manual del viajero, que es un texto compuesto por una introducción del propio autor y por seis capítulos en donde se contextualiza históricamente a la Ciudad de México, describiéndosela posteriormente en su actualidad urbana, costumbrista y literaria, realizándose en los dos últimos capítulos

6- Algunos estudiosos consideran que las guías de viaje son prácticas discursivas que pueden rastrearse en la literatura occidental desde el siglo XVII, junto con los relatos de viajes surgidos en la época (vid. Doiron 1988: 86); otros, incluso, llegan a explorarlas en la literatura griega, en la Historia de Heródoto (siglo V a. C.), en La descripción de Grecia, de Pausanias o en la Geografía de Estrabón (siglo I a. C.).

. Quizás sean pertinentes esas indagaciones en cuanto a la estructura o los recursos, no en cuanto a la finalidad y sentido de los textos modernos.

7- Ya un año antes, en 1857, la misma casa librera le había encargado a Arróniz el diseño y escritura del Manual de biografía mexicana o galería de hombres célebres de México, el cual había tenido una excelente acogida por parte del público mexicano, en un momento de la historia cultural del país en el cual se articulaba el imaginario nacionalista. Dicha publicación le granjeó un gran reconocimiento al autor. 
una ubicación y reseña geográfica y cultural a nivel nacional en la que está situada la capital. Manifiesta la certeza de la época referida a la necesidad no sólo de conocer física y geográficamente un lugar, la Ciudad de México en este caso, sino también su vida científica, literaria y filantrópica, como "termómetro para graduar la ilustración de un país”, dice su autor (Arróniz, 2014: 7), en una concepción heredera de los planteamientos prerrománticos del Sturm und drang que Madame de Staël ayudó a divulgar en el mundo latino. Por tal razón, el texto se da a la tarea de

presentar a la vista de cualquier viajero todo lo que pudiese interesarle y estuviera en relación con lo útil y pintoresco, refutando con ejemplos irrecusables a esos autores [extranjeros como Michel Chevalier, Isidor Lowestern o Madame Calderón de la Barca] que se han ocupado ligeramente y con malevolencia de nuestra querida patria, la que, sean cuales fueren sus errores y desgracias, merece un tributo de admiración y respeto del mundo civilizado (Arróniz 2014: 7).

En este sentido, hay una intención contestataria palmaria propia del contexto de definición histórica y cultural en el que se encontraba México durante la época y que conduce a la reelaboración, redescubrimiento y reescritura discursiva e icónica de México y el mexicano.

El narrador del texto define y desarrolla consciente y congruentemente la poética discursiva del $\mathrm{Ma}$ nual del viajero en México, misma que enuncia de la siguiente manera:

Nos hemos servido en nuestros trabajos de obras notables dadas a luz recientemente, del Diccionario publicado por el señor Escalante, de varias publicaciones periódicas, reuniendo elementos dispersos, reforzándolos con propias noticias y observaciones, escribiendo cosas originales y a veces copiando algunas noticias importantes o presentándolas en extracto, aunque siempre derivadas de autores dignos de mayor crédito y renombre (Arróniz, 2014: 8).

Como puede advertirse, la conformación y articulación del Manual del viajero responde a la noción discursiva-estilística de ser una especie de compendio o síntesis que organiza los conocimientos geográficos, históricos y culturales de un país en una época determinada; sin embargo, a diferencia de los grandes repertorios ilustrados que buscaban ampliar los horizontes culturales de la colectividad, los manuales o guías de viaje estaban dirigidos a la élite no sé si intelectual, pero sí definitivamente material que podía acceder al mundo, para lo que le ofrecían un conocimiento "selecto" en aras de conformar una imagen representativa y a la vez familiar de esa parte del mundo que se conocía.

Es en esta tradición cultural y discursiva, precisamente, que se tiene que ubicar el Manual del viajero en México o compendio de la historia de la ciudad de México, de Marcos Arróniz. Y también en ella es que tiene que reconocerse la resolución artística, ética y estética, a partir de la cual el autor ha seleccionado

mil objetos de recreo y magnificencia, que han ignorado o no han sabido comprender escritores que han pintado a México como un desierto estéril y a sus habitantes casi al nivel de las tribus bárbaras de la frontera [...por lo que] para estos precisamente es que 
hemos entresacado estas pruebas [que conforman al Manual de viajero], entre otras muchas, de que no han visto a México o lo han descrito al antojo de su fantasía y con miras a siniestras intenciones [expansionistas] (Arróniz 2014: 189; el subrayado es mío).

En este contexto, considero que los principales méritos de la resolución discursiva planteada por el Manual del viajero en México, de Marcos Arróniz, son tres. El primero de ellos radica en la cualidad narrativa del enunciado, que superando la mera y mecánica enumeración acumulativa de direcciones, datos, fechas y costos, alcanza a articular un entramado discursivo que no se reduce sólo a describir e informar, sino que salpimienta su guía orientativa ya con certeros y contundentes juicios, ya con jugosos comentarios basados algunos en interpretaciones históricas, los más apoyados en las leyendas y consejas populares; ya con comparaciones, hipérboles o señalamientos líricos y sensoriales que contribuyen a darle una perspectiva y sentido artísticos a la guía, hecho que homologa, que integra al discurso, dándole al mismo tiempo una cualidad estética. Por poner sólo un ejemplo, tal puede apreciarse cuando se expone la disposición arquitectónica de la derruida capital del imperio azteca, la que se describe de la siguiente manera:

Muchas de las islas [que formaban a la gran Tenochtitlán] brotaban del seno de las aguas diversificando graciosamente sus movibles cristales, y tachonando esta especie de piel de plata con manchas de verde y aterciopelado césped. Y si agregamos a estas bellezas de poéticos encantos esos ramilletes de las flores más exquisitas de espléndidos colores y delicados perfumes llamados "chinampas", con los que jugando graciosamente las ondas los hacían cambiar de lugar y mantenían en ellos una frescura eterna, nada podría exceder a tan maravilloso espectáculo. Este cuadro tomaba más vida con el hormigueo incesante de una multitud de gentes que, ya en las graciosas canoas o llenando las calles, ocupábanse del comercio y sus quehaceres (Arróniz, 2014: 15; el subrayado es mío).

El otro acierto del Manual de viajeros me parece radica en el conocimiento de la tradición costumbrista mexicana de los cuadros de tipos, escenas y paisajes. Y es que el texto entra en diálogo casi directo con otras obras del mismo género en la época, tanto con esas cimas del primer costumbrismo mexicano que son Los mexicanos pintados por sí mismos y México y sus alrededores, como también con los planteamientos de tipos y escenas escritos por coetáneos del autor como Hilarión Frías y Soto, José María Rivera o, incluso, su cercanísimo y dilecto Florencio María del Castillo. Al respecto no puedo dejar de señalar que en el capítulo tercero titulado "Trajes, usos y costumbres" --el más logrado artísticamente del compendio--, el narrador consigna la cultura de la plaza dentro de las costumbres cotidianas mexicanas. Para ello describe el "Paseo de las Cadenas de la Ciudad de México", mismo que, dice el narrador,

es muy característico de la ciudad de México y lo forma una banqueta alrededor del cementerio [que está en el atrio] de la Catedral, realzada de trecho en trecho por unos postes modernos de mampostería y enlazados por gruesas cadenas [que le dan su nombre...] Este [paseo] cobra un encanto indefinible cuando a los dulces rayos del 
astro de plata se ve a un lado la inmensa plaza reverberando con las multiplicadas y rojizas luces de su alumbrado y allá muy lejos los arcos de los portales inundado de luz; por la parte contraria se despliega ancha y elevada la Catedral, que dibuja sus torres robustas e inmóviles en el sereno firmamento. El Palacio cerrando a un lado la plaza, con su lisa fachada sembrada de numerosos balcones y ventanas, sus torreones en los ángulos y su almenada azotea (Arróniz, 2014: 107).

Tres años antes, en 1855, como parte de México y sus alrededores. Colección de vistas, trajes y escenas costumbristas, apareció el binomio plástico/literario titulado "Las cadenas en una noche de luna", firmada la parte narrativa por Florencio María del Castillo, el cercanísimo amigo de Arróniz.

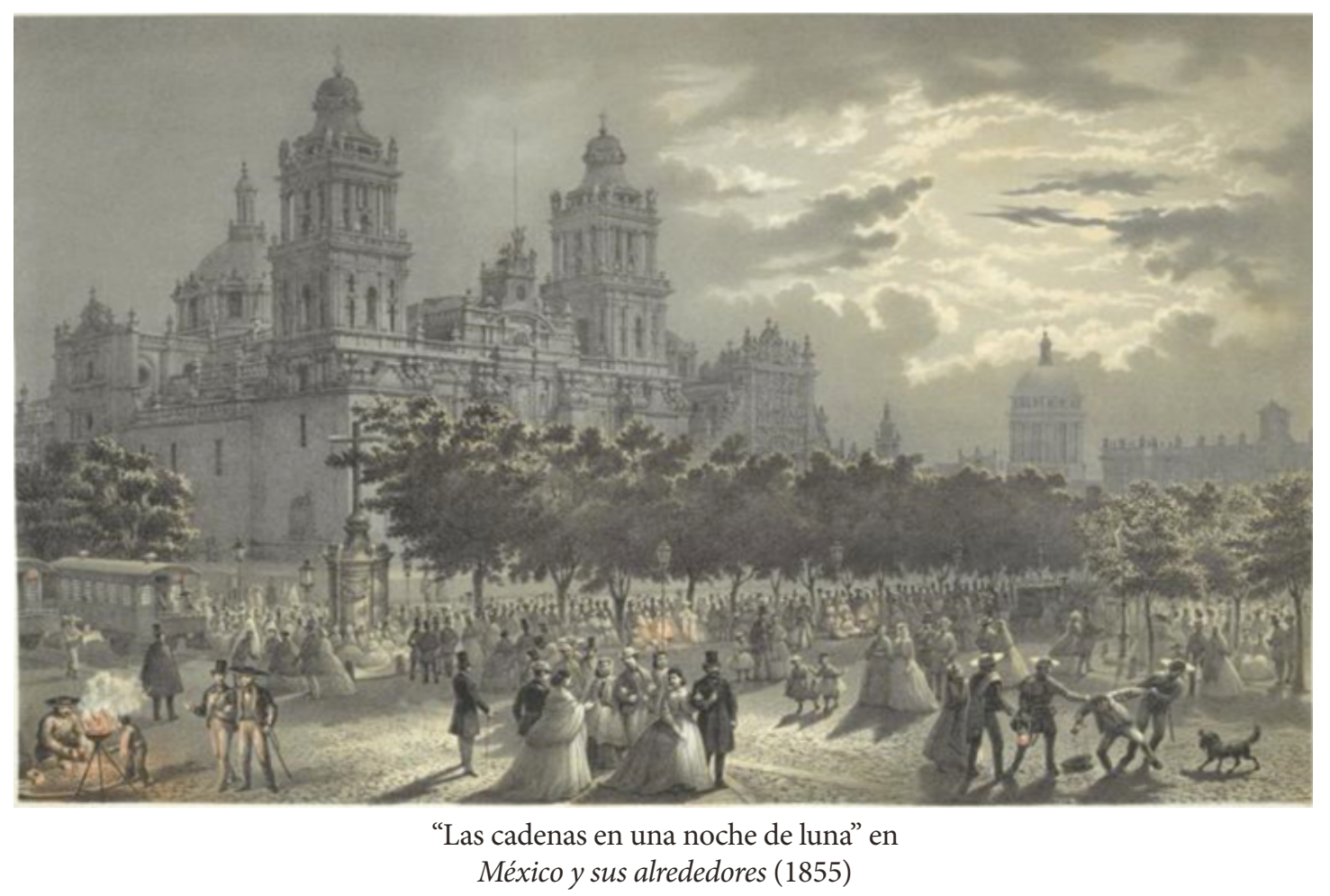

El logro artístico de la litografía es único por la melancolía del horizonte que contrasta con la vitalidad de la escena y considero que pocas o ninguna imagen más representativa y romántica del México decimonono que esa; sin embargo, hay que reconocerlo también, la parte literaria del cuadro no está a la misma altura, no sólo por lo escueto sino por lo inexpresivo, lo mecánico y lo común de sus señalamientos. Precisamente en diálogo con este cuadro (y en otros pasajes del Manual con otras representaciones iconográficas de México y el mexicano como "La calle de Roldán” o "El paseo de la Viga”), Marcos Arróniz dialoga tácita pero críticamente con la tradición costumbrista mexicana de los cuadros de tipos, escenas y paisajes, revelando así tanto las posibilidades del género en México como la renovación artística que hubiera podido desarrollar el poeta. 
Ya para cerrar este trabajo, quiero señalar el que considero el más importante y sensible de los méritos de Marcos Arróniz como narrador de cuadros de costumbres, del Manual del viajero en México como enunciado literario y cultural relativamente autónomo y autosuficiente. Me refiero a la perspectiva del narrador que busca no sólo describir la realidad cultural mediante la relación de los "mil objetos de recreo y magnificencia" que caracterizan al entorno mexicano, sino que, sobre todo, como lo señala con insistencia tanto en éste como en otros de sus textos costumbristas, busca captar principalmente "todo, todo [lo que] presenta vida, movimiento y alegría" (Arróniz 1855: 6; el subrayado es mío). Y es que a diferencia de los otros narradores de los cuadros de costumbres, que, en aras de destacar, explicar y concientizar las virtudes y los defectos del hombre y la cultura mexicana objetos de la representación artística, asumían un punto de vista fotográfico, fijo y estático, que caracterizaba perfectamente, sí, al tipo cultural o a la escena costumbrista o al paisaje, pero de una manera inmóvil, inmutable, acartonada pudiera decirse, Marco Arróniz, en cambio, en el Manual del viajero en México o compendio de la historia de la ciudad de México (y en sus otros cuadros costumbristas, como "La Fuente de la Tlaxpana"), logra trascender esa perspectiva retratista pasiva, y capta el dinamismo de la cotidianidad de tipos, escenas y paisajes, a partir de visualizarlos integradamente, en un juego de correlaciones que permiten captar el vínculo e interdependencia del hombre con el medio físico y cultural. Al menos así sucede en el apartado que da cuenta de los pregones cotidianos de los vendedores, aspecto de la cultura popular mexicana que llamó la atención de propios y extraños, pero que a diferencia de Madame Calderón de la Barca en La vida en México (1844), de Hilarión Frías y Soto en Álbum fotográfico (1868), o del mismísimo Guillermo Prieto en varias de sus crónicas, Arróniz llega a representar en toda su vitalidad y dinamismo, logro debido, quizás, sólo a su exposición descriptiva no necesariamente explicativa ni valorativa; así sucede, también, con la relación de la vestimenta típica de la mujer pudiente en la época, en la que lo importante, más que la relación del uso de sayas y mantillas, es que logra captar discursivamente el ludismo efecticista del juego y movimiento de terciopelos y encajes; otro tanto pudiera decirse de los cuadros o escenas costumbristas que refieren a las posadas, a las festividades (sacras y profanas) de cuaresma y de los bautizos o, particularmente, a la celebración de los días de campo, los que el narrador introduce de la siguiente manera:

[Luego de días y semanas de organización y de soñar con la puesta en marcha,] por fin llega el suspirado momento, la fecha de eterna recordación en el libro de la vida que es la cocina, el más comúnmente preferido en las bibliotecas de la época, y el más estudiado por la humanidad civilizada. Todo está listo. Y sólo aguarda aquella tribu errante que se asome la rubicunda aurora por los balcones del oriente a ver pasar la famosa comparsa [compuesta por los paseantes de todas las edades]. Suena la hora; los coches se llenan; las sillas de los caballos se ocupan; las municiones de campaña[, es decir, la comida,] se acondicionan, y comienza el movimiento (Arróniz, 2014: 101; el subrayado es mío).

...Tipos, escenas y paisajes con "vida, movimiento y alegría" es lo que representa artísticamente el narrador en el Manual del viajero en México o compendio de la historia de la ciudad de México y lo que ofrece a los lectores de su texto, originalizando así su obra y diferenciándose de sus contemporáneos. Interesante hubiera sido conocer la evolución ética y estética que esas certezas artísticas y vitales hubieran 
tenido en la obra posterior del poeta y narrador y, concretamente, la manera como hubieran incidido en la renovación de la tradición costumbrista mexicana. Desafortunadamente, la muerte prematura de Marcos Arróniz nos deja sólo en el terreno de las suposiciones.

\section{Referencias}

Arróniz, Marcos. 2014. Manual del viajero en México o compendio de la historia de la ciudad de México. México: CONACULTA.

.1855. La fuente de la Tlaxpana. En México y sus alrededores. Colección de vistas monumentales, paisajes y trajes del país, editado por Joseph Decaén. México: Taller litográfico de Joseph Decaén, 6.

Bobadilla Encinas, Gerardo Francisco. 2013. Literatura y cultura mexicana del siglo XIX. Hermosillo: Editorial Universidad de Sonora.

Brading, David. 1997. Los orígenes del nacionalismo mexicano. México: Editorial Era.

Campos, Marco. 2005. Vida y obra de Marco Arróniz. Literatura Mexicana, 16(2): 117-157.

. 2007. Estudio introductorio. En Marco Arróniz, La lira rota, compilado por Marco Antonio Campos. México: UNAM, 8-67.

Decaén, Joseph (ed.). 1855. México y sus alrededores. Colección de vistas monumentales, paisajes y trajes del país. México: Taller litográfico de Joseph Decaén.

Doiron, Norman. 1988. Lart de voyager. Pour une définition du récit de voge á lépoque classique. Poétique, 73: 83-108.

Fernández, Ángel. 2005. Marcos Arróniz y sus amigos del Liceo Hidalgo. En La república de las letras. Asomos a la cultura escrita del México decimonónico vol. 3, editado por Belem Clark de Lara y Elisa Speckman Guerra. México: Universidad Nacional Autónoma de México, 131-147.

Martínez, José. 1955. La emancipación literaria de México. México: Antigua Librería Robredo.

Martínez, Marina. 2011. El manual de viajeros de Marcos Arróniz. Literatura Mexicana 22(1): 75-97.

Martínez, Esther. 2008. Reseña. Signos Literarios 7: 133-137.

Pimentel, Francisco. 1892. Historia crítica de la poesía en México. México: Oficina tipográfica de la Secretaría de Fomento.

Ramírez, Ignacio. 1996. La desespañolización. En La misión del escritor. Ensayos mexicanos del siglo XIX, compilado por Jorge Ruedas de la Serna. México: UNAM, 189-192.

Schneider, Luis. 1975. Ruptura y continuidad. La literatura mexicana en polémica. México: Fondo de Cultura Económica.

Toussaint, Manuel. 1934. La litografía en México. México: Ediciones Neolitho.

Zarco, Francisco. 1855. La fuente del Salto del agua. En México y sus alrededores. Colección de vistas monumentales, paisajes y trajes del país, editado por Joseph Decaén. México: Taller litográfico de Joseph Decaén, 4-6. 